\title{
Hepatic hemangioma: An unusual cause of fever of unknown origin
}

\author{
KATHLEEN HOPKINS, MD, ROBERT J BAILEY, MD, FRCPC
}

ABSTRACT: A patient with a giant cavernous hemangioma of the liver presented with fever of unknown origin. Extensive investigation revealed no other source of temperature. Following surgical resection of the lesion the fever resolved. Pathology of the benign cavernous hemangioma showed only areas of thrombosis. Can J Gastroenterol 1990;4(6):227-229

Key Words: Cavernous hemangioma, Fever, Hepatic resection

\section{Hémangiome hépatique: Cause inhabituelle d'une fièvre d'origine inconnue}

RESUME: Un patient atteint d'un angiome caverneux géant au niveau du foie présentait une fièvre d'origine inconnue. Un examen approfondi ne révéla aucune autre source possible. La fièvre est tombée après résection chirurgicale de la lésion. La pathologie de l'angiome caverneux bénin n'a mis en évidence que quelques régions thrombosées.

\footnotetext{
F
}

EVER OF UNKNOWN ORIGIN REmains an intriguing and challenging clinical problem despite advances in diagnostic capabilities. While the liver is a known source of fever, it is usually due to an infectious process, whether viral, bacterial, parasitic or tuberculous. In this case report, a noninfectious hepatic cause of a persistent spiking temperature was demonstrated.

\section{CASE REPORT}

A 46-year-old female of Korean background was admitted with right upper quadrant abdominal pain. One year previously a giant cavernous hemangioma of the liver had been diagnosed after investigation of a liver mass. The pain was pleuritic, sharp and localized to below the right costal margin. She denied fever or chills. There was no history of alcohol abuse or tuberculosis. She was not on any medications.

Abdominal examination revealed a hepatic rub and a liver span of $18 \mathrm{~cm}$ at the midclavicular line, unchanged from the previous year.

Hemoglobin and platelets were normal. Aspartate aminotransferase was 38
iu/L (normal 10 to 50 ), alkaline phosphatase $335 \mathrm{iu} / \mathrm{L}$ (normal 85 to 265) and bilirubin $22 \mu \mathrm{mol} / \mathrm{L}$ (normal 2 to 20 ).

Computed tomography scan had shown no change over the year, with a hypodense lesion in the right lobe of the liver measuring 18 by $14 \mathrm{~cm}$ (Figure $1)$. The patient's symptoms were controlled with codeine and acetaminophen.

The patient presented one month later with increased right upper quadrant pain, night sweats, fever, chills, anorexia and a nonproductive cough. There had been no improvement on penicillin G $300 \mathrm{mg}$ four times daily for two weeks. She was readmitted to hospital.

Physical examination revealed a blood pressure of $110 / 80 \mathrm{mmHg}$ and a temperature of $38.2^{\circ} \mathrm{C}$. The chest was clear to auscultation. No murmurs were heard. The hepatic rub persisted and the liver span was unchanged.

Hemoglobin was now $10 \mathrm{~g} / \mathrm{dL}$, white blood count $7900 / \mathrm{mm}^{3}$ with $68 \%$ neutrophils, $3 \%$ bands, $18 \%$ lymphocytes, $10 \%$ monocytes and $1 \%$ eosinophils; it remained so throughout the admission. Platelets were adequate at $330,000 / \mathrm{mm}^{3}$.

Coomb's test was negative. The patient was hepatitis B surface antigen negative and antibody positive. Prothrombin time was $11 \mathrm{~s}$ (normal 10.4 to 13.2). Aspartate aminotransferase was $87 \mathrm{iu} / \mathrm{L}$, alkaline phosphatase $653 \mathrm{iu} / \mathrm{L}$ 

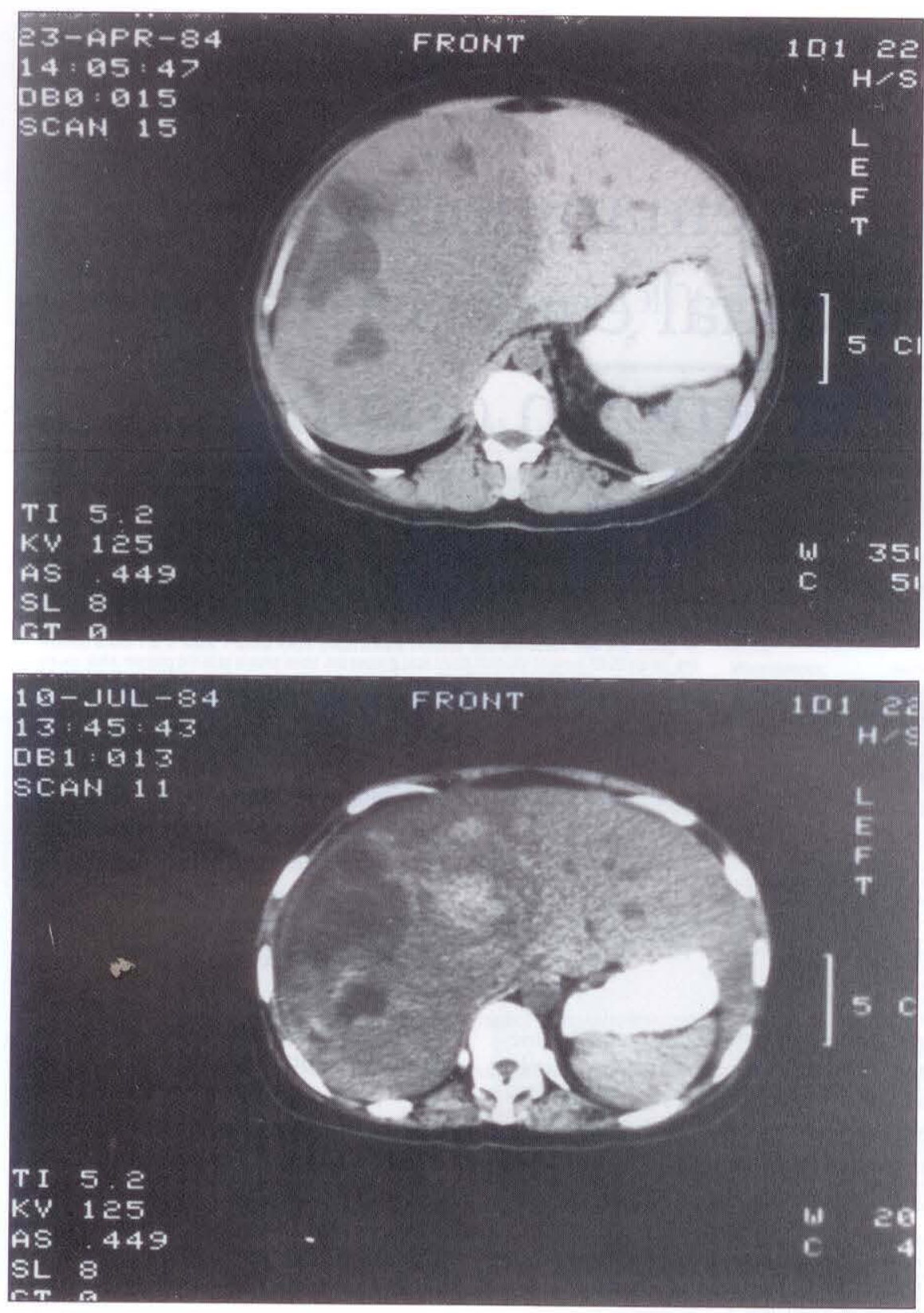

Figure 1) Unaugmented computed tomography scan of the liver. Top April. There is a large irregular homogeneous hypodense lesion occupying the entire right lobe of the liver, with cystic areas within the lesion. This scan is unchanged from the previous year. Bottom July. There are now adverse changes with the cystic lesions increasing in size and number; the attenuation has increased in multiple areas within the lesion, presumably due to recent hemorrhage

and bilirubin $20 \mu \mathrm{mol} / \mathrm{L}$. Serum iron was $4 \mu \mathrm{mol} / \mathrm{L}$ (normal 10 to 40 ) with a total iron binding capacity of 39 $\mu \mathrm{mol} / \mathrm{L}$ (normal 40 to 75 ), and the ferritin was consistently greater than 500 $\mu \mathrm{g} / \mathrm{L}$ (normal 24 to 155). Serum protein electrophoresis had increased alpha- 1 and slightly increased alpha-2 globulin, suggesting tissue necrosis. Mantoux was positive to five tuberculosis units. Urinalysis showed 0 to 2 leukocytes per high power field and 21 to 30 erythrocytes per high power field and a few bacteria with no significant growth. Sputum and urine cultures were negative for tuberculosis. Bone marrow culture did not grow acid-fast bacilli; plasmacytosis $(6 \%)$ was the only abnormality. Cytomegalovirus titre was 1:8. Malaria smear and viral and fungal serologies were negative. Antinuclear and rheumatoid factors were not detected. There was no growth on repeated blood cultures.

The patient continued to have pyrexia despite acetylsalicylic acid 650 mg every $4 \mathrm{~h}$.

Chest $\mathrm{x}$-ray demonstrated elevation of the right hemidiaphragm; otherwise it was normal. Ultrasound of the ab. domen again revealed the mass, unchanged in size but with a complex region in the centre containing cystic areas. Displacement of the right kidney by the liver mass was the only abnormality on the intravenous pyelogram. Echocardiogram was normal. No focus of infection was seen on gallium scan and no tracer taken up by the heman. gioma. Computed tomography scan reported adverse change with lower attenuating areas increasing in size and number (Figure 1).

A trial of isoniazid $300 \mathrm{mg}$ daily, rifampin $10 \mathrm{mg} / \mathrm{kg}$ daily, ethambutol 15 $\mathrm{mg} / \mathrm{kg}$ daily and pyridoxine $100 \mathrm{mg}$ daily was initiated. Despite this, elevated temperatures continued (Figure 2).

The patient was seen in consultation and right hepatic lobectomy was recommended. Cefoxitin $2 \mathrm{~g} 1 \mathrm{~h}$ preoperatively and four doses postoperatively were given. The temperature subsided and was normal within $24 \mathrm{~h}$ of surgery; it remained so until discharge three weeks later. Pathology of the lesion revealed a $1790 \mathrm{~g}$ cavern. ous hemangioma with areas of focal thrombosis.

At follow-up one year later the patient remains well and pain free. Liver function tests, hemoglobin and ferritin returned to normal. A computed tomography scan showed com. pensatory hypertrophy of the remaining liver.

\section{DISCUSSION}

Hepatic hemangiomas are estimated to occur in approximately $5 \%$ of the population, being most prevalent in the third, fourth and fifth decades of life. Giant hemangiomas, which represent only a small number of all hemangiomas, are defined as those measuring more than $4 \mathrm{~cm}$ in diameter (1).

Several known complications of giant hemangiomas include hypofibrin. ogenemia, thrombocytopenia and 


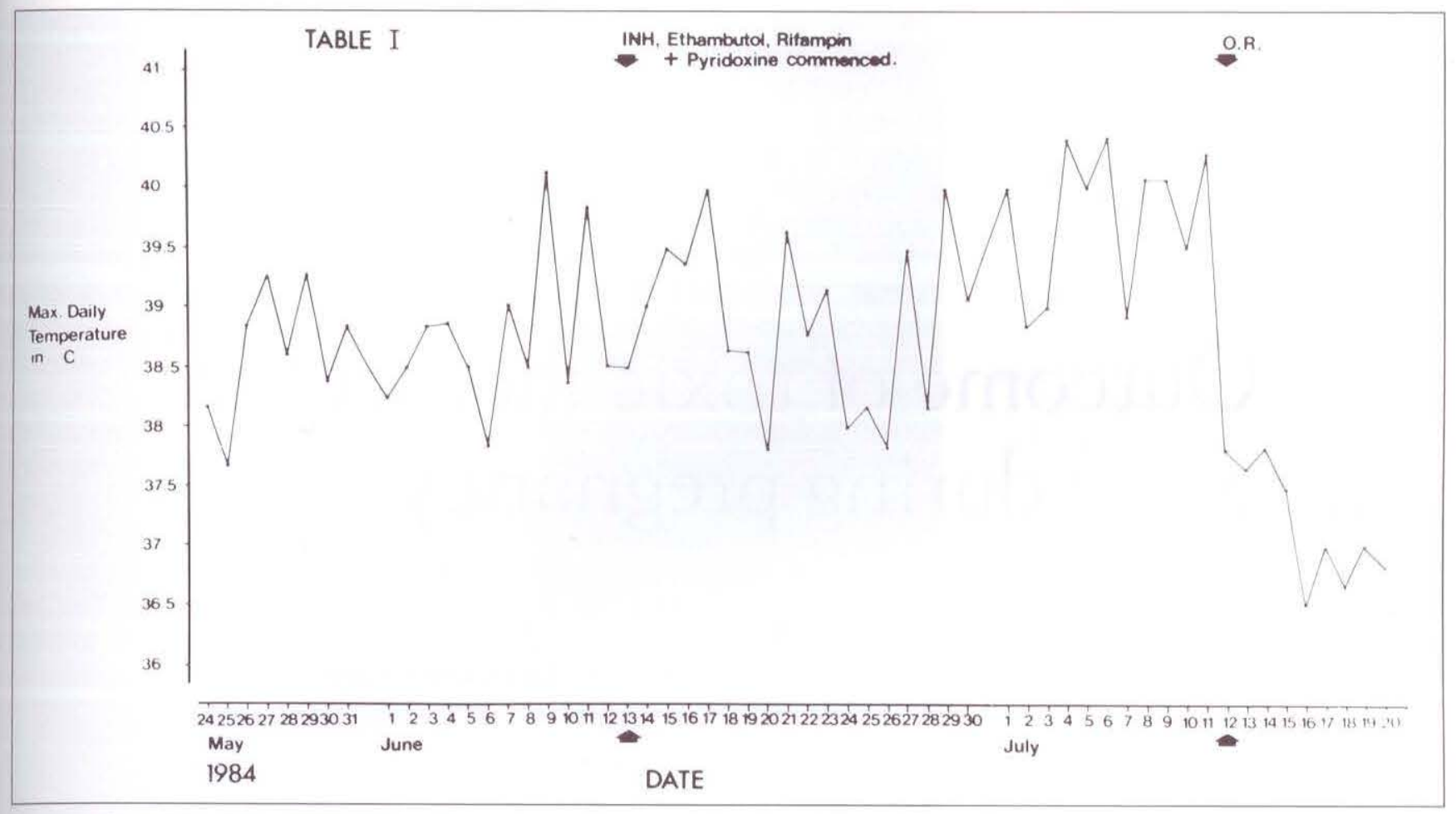

Figure 2) Recorded daily maximum temperature. There was no benefit from acetylsalicylic acid $650 \mathrm{mg}$ every 4 h or antituberculous medications

hemorrhage. Fever,without other sources has also been described in seven patients (2-6); of these, it was noted to have a spiking pattern in three (4-6). The mechanism by which these benign tumours produce pyrexia is unknown. However, the Kupffer cells in the liver, being of macrophage lineage, are a source of endogenous pyrogens (7). Theoretically, their continued destruction or stimulation by degeneration of the lesion could have been one source of nonseptic fever.

While most hemangiomas remain

\section{REFERENCES}

1. Sherlock S. Hepatic tumours. In: Sherlock S, ed. Diseases of the Liver and Biliary system, 8 th edn. Oxford: Blackwell Scientific Publications, 1989;28:584-617.

2. Shumacker HB Jr. Hemangioma of the liver. Surgery 1942;1 1:209-22.

3. Kato M, Sugawara I, Okada A, et al. Hemangioma of the liver. Am J Surg 1975;129:698-704.

4. Levitt LM, Coleman M, Yarvis J. Multiple large hemangiomas of the asymptomatic, symptomatic hemangiomas present a management problem. Radiation has been used successfully for unresectable lesions, but the results are not always predictable. Moore (8) has reported one case of hepatoma as a late sequelae of hepatic irradiation for hemangioma; radiation hepatitis is also a side effect. According to a recent review (9), radiotherapy should not be considered an acceptable treatment modality. Corticosteroids have been shown to be effective in treating symptomatic hemangiomas in both adults

liver. N Engl I Med 955;252:854-5.

5. Okazaki N, Yoshino M, Yoshida T,

Ohno T, Kitagawa T, Hattori N.

Radiotherapy of hemangioma cavernosum of the liver. Gastroenterology 1977;73:353-6.

6. Fenster LF, Freeney PC, Beebe HG. Cavernous hemangioma of the liver presenting with fever - Successful treatment with prednisone. West J Med 1978;129:138-40.

7. Bernheim HA, Block LH, Atkins E. Fever: Pathogenesis, pathophysiology,
(6) and children (10). The well known wide spectrum of adverse reactions to corticosteroids and unknown duration of treatment make this a less desirable option.

The present patient had a potentially resectable lesion with unremitting symptoms. Embolization has been suggested as a first alternative for symptomatic hemangiomas (9); however, multiple procedures may be necessary. For this patient, elective hepatic resection offered safe and effective treatment.

and purpose. Ann Intern Med 1979;91:261-70.

8. Moore TA, Ferrante WA, Crowson TD. Hepatoma occurring two decades after hepatic irradiation.Gastroenterology 1976;71:128-32.

9. Anon. Hepatic haemangioma-A suitable case for treatment? Lancet 1988;ii:882-4. (Edit)

10. Goldberg SJ, Fonkalsrud E. Successful treatment of hepatic hemangioma with corticosteroids. JAMA 1969;208:2473-4. 


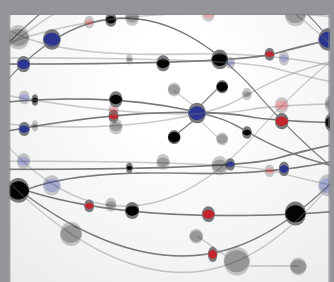

The Scientific World Journal
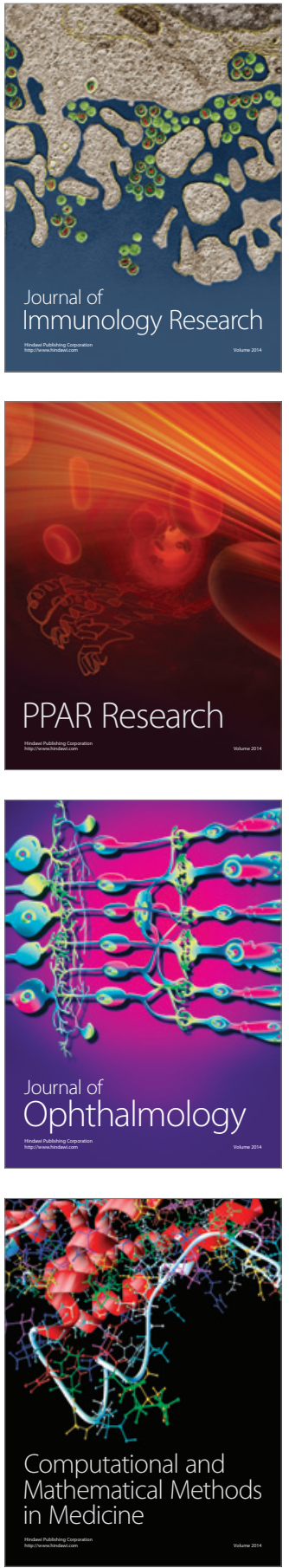

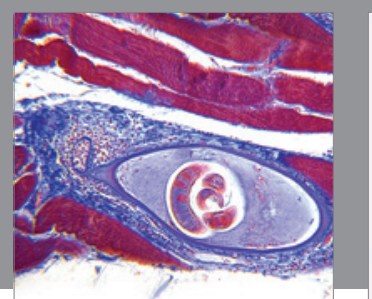

Gastroenterology Research and Practice

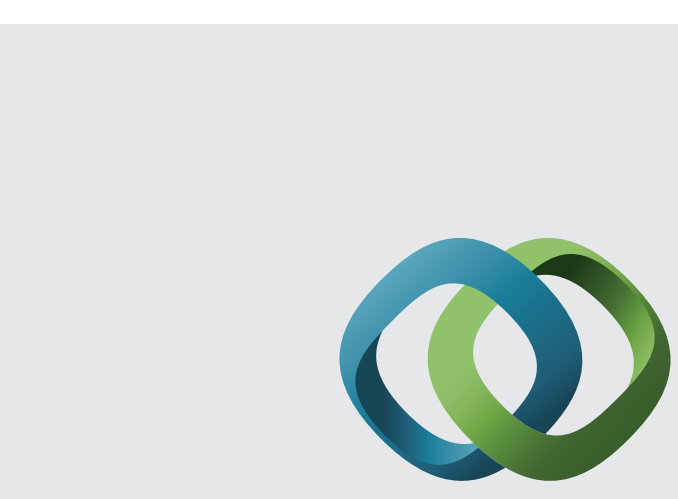

\section{Hindawi}

Submit your manuscripts at

http://www.hindawi.com
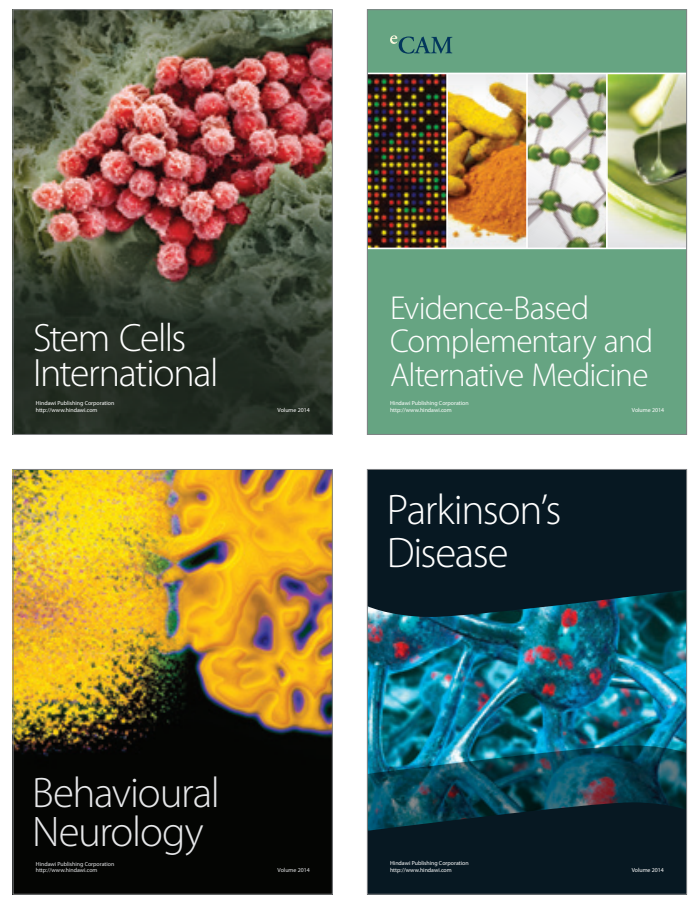
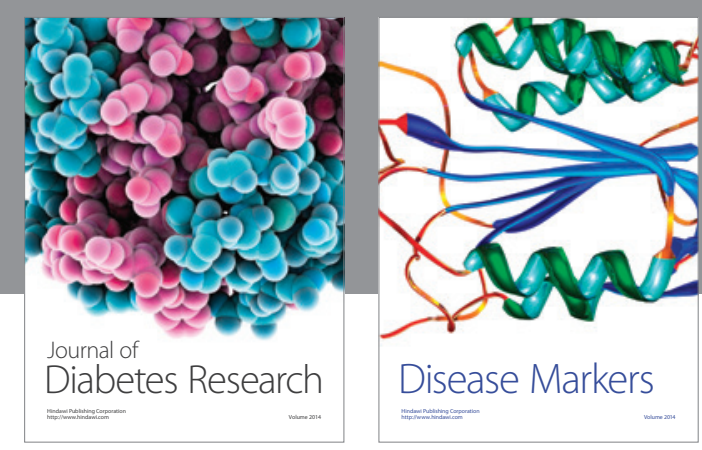

Disease Markers
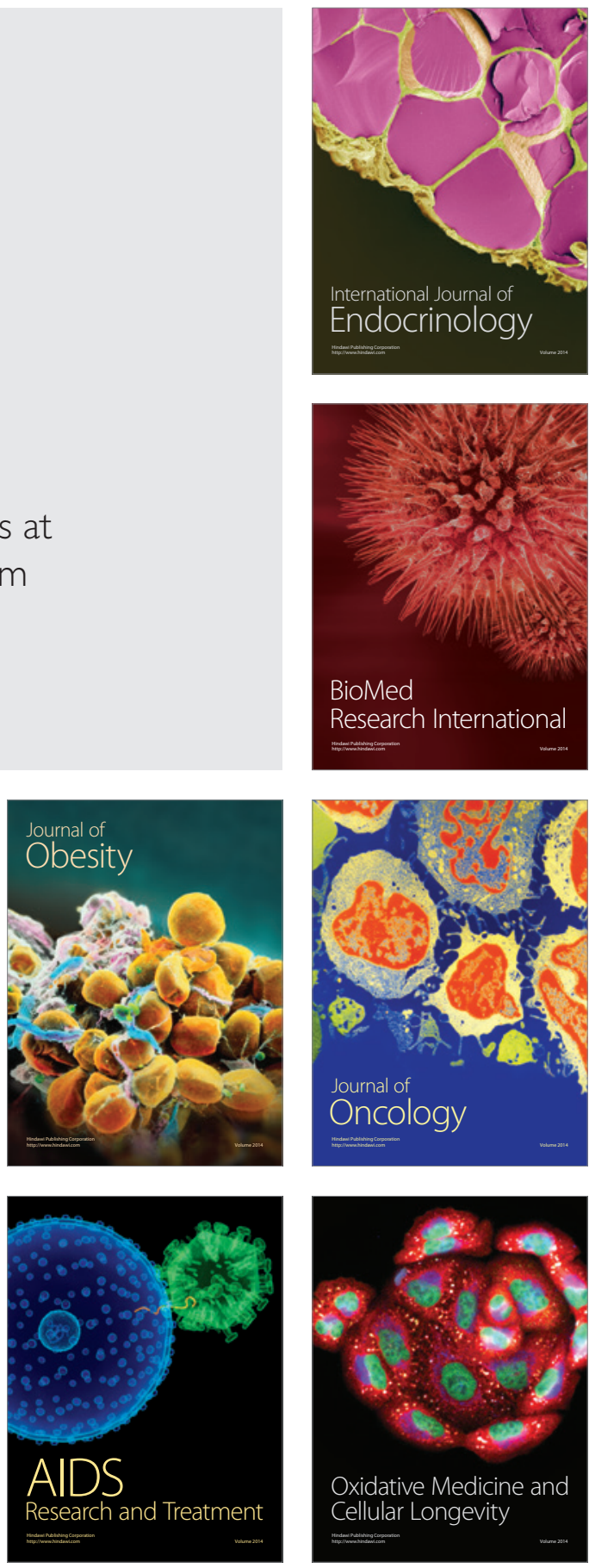